\title{
Detecting fragmentation of cover in desert grasslands using line intercept
}

\author{
ROBERT O. KUEHL, MITCHEL P. MCCLARAN, AND JUSTIN VAN ZEE
}

Authors are professor emeritus, Statistical Support; associate professor, Range Management, College of Agriculture, University of Arizona, Tucson, Ariz. 85721; and biological soils technician, USDA-ARS, Jornada Experimental Range, New Mexico State University, Las Cruces, N.M. 88003.

\section{Abstract}

Changes in the amount or spatial distribution of grass plants are thought to be indicative of the stability of desert grasslands. This study assessed, through simulation, the sensitivity of statistical properties for distance between plants (fetch length), measured with a line intercept transect, to changes in the spatial distribution and amount of plant cover. Monitoring plots, $30 \times 30 \mathrm{~m}$, were simulated for $1,2.5,5,10$ and $15 \%$ grass cover with random and fragmented spatial distribution. Fetch lengths were measured on 2 randomly placed $30 \mathrm{~m}$ transects. In addition to the median and interquartile range, the asymmetry of the sampling distributions was measured with a ratio [(maximum-median)/(medianminimum)] that would identify the presence of at least 1 large open space. The accuracy of the fetch length method was confirmed by the similarity of its sampling distribution to that for the well known random point-to-plant sampling procedure. In both the fetch length and the point-to-plant measures, the median and interquartile range increased with decreasing cover for random and fragmented distribution. The asymmetry estimate increased sharply with increasing cover for the fragmented distribution but asymmetry was nearly constant with increasing cover for the random distribution. The results suggest that the evaluation of changes over time at a monitoring site could use fetch lengths measured along a line intercept transect to detect changes in both absolute and spatial arrangement of cover.

Key Words: fetch length, monitoring, simulation

In desert grasslands, changes in the amount or spatial distribution of grass plants are thought to contribute to the potential for soil erosion, the conversion from grass to shrub vegetation, and the redistribution of soil nutrients from fine-scale (centimeters), associated with grasses, to larger-scale (meters), associated with shrubs (Schlesinger et al. 1990, Weltz et al. 1998). Furthermore, these changes tend to create positive feedbacks that reinforce their trends and permanence. Until recently, detecting changes in the spatial distribution of grass cover had received very little attention for purposes of rangeland monitoring compared to efforts to detect changes in absolute amount of grass cover (Tongway and Hindley 1995, de Soyza et al. 1997, Whitford et al. 1998). These recent efforts are beginning to address the infor-

The Arizona Agricultural Experiment Station and The University of Arizona provided partial financial support for this work, and E.L. Smith and G.B. Ruyle provided helpful comments during the formative stages of this work.

Manuscript accepted: 17 Apr. 2000.

\section{Resumen}

Se piensa que los cambios en la cantidad de distribución espacial de las plantas de zacates desérticos son un indicador de la estabilidad de los pastizales desérticos. Este estudio evalúa, a través de simulación, la sensibilidad de las propiedades estadísticas de la distancia entre plantas medida con transecto de línea de intercepción a los cambios en la distribución espacial y la cantidad de cobertura vegetal. Se simularon 30 parcelas de monitoreo de $6 \times 30 \mathrm{~m}$ con 1, 2.5, 5, 10 y $15 \%$ de cobertura de zacates con una distribución aleatoria y fragmentada. La longitud entre plantas se midio en 2 transecto de $30 \mathrm{~m}$ colocados aleatoriamente, Además, de la mediana y el rango intercuartil se midió la asimetría de las distribuciones de muestreo con la relación [(máximo-mediana)/(mediana-mínimo)] que identificaria la presencia de al menos un espacio largo. La certeza del método de longitud entre plantas fue confirmada por la simiitud de su distribución de muestreo con la del procedimiento de muestro bien conocido de punto a planta. En ambos métodos (la distancia entre plantas y el punto a planta) la mediana y el rango intercuartil aumentaron al disminuir la cobertura de una distribución aleatoria y fragmentada. La estimación de la asimetría se incremento abruptamente al incrementar la cobertura de la distribución fragmentada, pero la asimetría fue casi constante con el incremento de la cobertura de la distribución aleatoria, Estos resultados sugieren que la evaluación de los cambios a través del tiempo en un sitio de monitoreo podría utilizar la distancia entre plantas medidas a lo largo de transectos de línea de intercepción para detectar los cambios tanto en la cobertura absoluta como su arreglo espacial.

mation needed to assess changes in the spatial distribution and connectivity of vegetation patches that are called for in the next generation of soil erosion prediction models to document trends in the fragmentation of plant cover on rangelands for the purposes of assessing rangeland health (National Research Council 1994, Weltz et al. 1998).

One way that grass cover can reduce soil erosion is by creating obstructions that slow the rate of overland flow of water because shorter distances between grass plants decrease the opportunity for water to acquire the energy needed to remove soil and litter from a site (e.g. Weltz et al. 1998). If the average amount of cover is reduced, either through the reduction of average plant size, the reduction of plant density, or some combination of size and density, the probability of longer distances between plants will increase. In addition, it is important to note that the probability of finding longer distances will also increase when the spatial 
arrangement of cover becomes more patchy even if absolute cover remains unchanged. Accordingly, rangeland monitoring efforts to detect changes in the potential for soil erosion should include measures of absolute as well as spatial arrangement of grass cover (National Research Council 1994, Weltz et al. 1998).

Recent attempts to include spatial distribution measures in rangeland monitoring have used the line intercept method (Canfield 1941) to record both percent cover and the distance between plants along a transect. Tongway and Hindley (1995) used the line intercept transect at a semi-arid savanna site in Queensland, Australia to measure the number of obstructions, distance between obstructions, obstruction width, and percent basal cover with the goal of documenting the potential for overland water flow and erosion. They used the term "fetch length" to describe distance between obstructions on the line intercept, and they found greater cover and shorter fetch lengths between plants on ungrazed than on grazed sites. In the desert grassland, de Soyza et al. (1997) and Whitford et al. (1998) used line intercept transects at desert grassland sites in southern New Mexico to estimate the size of bare soil patches in relation to grazing intensity along a piosphere gradient (distance from a livestock water development). They reported mean bare patch sizes that ranged from approximately 40 to $400 \mathrm{~cm}$ at different sites with percent cover ranging from more than $20 \%$ to less than $1 \%$, respectively. Using line intercept transects, de Soyza et al. (1997) found the arithmetic product of the average distance between plants and the skew of log-transformed distance between plants to be positively associated with increasing grazing pressure and Whitford et al. (1998) found the arithmetic product of average distance between plants and average percent bare ground to be positively associated with increasing grazing pressure.

At this early stage in efforts to detect changes in the spatial pattern of grasses during rangeland monitoring, it is important to examine the underlying assumptions of a sample design using the line intercept method. In particular, we suggest that an examination of the statistical properties of the sample distribution for fetch lengths will provide at least part of that needed evaluation. Specifically, it is important to examine the sensitivity of the line intercept method to changes in the arrangement of plants that are independent of changes in the abundance of plant cover. The line intercept transect is an attractive method because it traditionally has been employed to estimate percent cover and there is a considerable body of literature regarding the statistical properties of the intercept measure (see Kaiser (1983) for a comprehensive bibliography). We found no literature on the statistical properties of the line intercept measure for distance between plants or fetch length other than frequency distributions of fetch lengths measured on 4 sites in the Jornada Basin of the northern Chihuahuan Desert in southern New Mexico by de Soyza et al. (1997). They found that a logarithmic transformation of the fetch lengths led to near normal distributions, implying highly skewed distributions for fetch length. This evidence suggests some function of the mean or skew of the sample measurements of fetch length has some sensitivity to changing range conditions. However, it would be informative to have some knowledge of the general distributional properties of the fetch length measures to determine which properties of the sample distribution are most sensitive to changing spatial patterns of grass cover.

Measuring the distance to the nearest point from randomly located points is a proven and well studied method to assess the spatial arrangement of cover (Diggle 1983). The distance from the random point to the nearest point measures the size of empty spaces in a spatial point distribution. The statistical properties of these point to nearest event distances are well known and can be used to detect the degree of departure from complete spatial randomness. When points are distributed on a plane under complete spatial randomness, the probability density function for the point to nearest event distance has an exponential distribution (Diggle 1983), which has a positive (right) skew distribution, even under complete spatial randomness.

The reality of rangeland monitoring is that it is more traditional and more time efficient to use transects rather than establish numerous random sampling points. Therefore, in this study to detect changes in the spatial arrangement of cover, we used the better understood but more complicated random point to nearest event sampling technique as a benchmark to assess the sensitivity of the more easily applied fetch length distance along a line transect.

Our research objective was to assess the sensitivity of the statistical properties of distance between plants (fetch length) measured with a line intercept transect to changes in both the spatial distribution of plants and the abundance of plant cover. To reach this objective, monitoring plots in desert grassland vegetation were simulated for 5 different amounts of grass cover, each with either random or fragmented spatial distributions of plants. The sample distributions for the distance between plants on the line intercept transect were compared with the distributions for distance between random points and plants. The sensitivity assessment used 3 simple statistical properties of distance measures (median, interquartile range, and asymmetry) and compared them across the 5 levels of cover and the random versus fragmented spatial distributions. Finally, we performed a simple validation of the simulations using the distance between plants measured along line intercept transects from 6 desert grassland locations.

\section{Methods}

\section{Simulation of cover and spatial pattern}

Programs were written in the $C$ programming language to simulate the spatial distribution of basal cover of perennial grasses on desert grassland range sites and to simulate measurements from line intercept and random point-to-plant distance samples. The simulations were scaled to simulate sample plots of $30 \times 30 \mathrm{~m}$ with $1,2.5,5,10$, and $15 \%$ basal cover. Spatial patterns simulated were (1) a random and (2) a fragmented distribution of plants. The fragmented pattern was simulated using a random distribution of plants fragmented with a random distribution of bare patch areas comprising $25 \%$ of the total area (Fig. 1a, 1b).

The random distribution of plants without bare patches was simulated in a single stage. Plant basal area was represented by a disc scaled to a $5 \mathrm{~cm}$ diameter. To prevent the overlap of any 2 plants, the coordinate points, representing the centers of the plant, were simulated with an algorithm designed to generate a sequential spatial inhibition (SSI) process (Matérn 1960). The SSI process sequentially lays down discs with a radius of inhibition $r$ that do not overlap existing discs. Thus, any 2 points representing the centers of 2 plants' basal areas were at least $5 \mathrm{~cm}$ apart to avoid overlap. The fragmented surface was simulated in 3 stages. The first stage simulated bare patches on $25 \%$ of the total plot area as non-overlapping disks with a $300 \mathrm{~cm}$ diameter located randomly on the surface. Bare patch sizes of $300 \mathrm{~cm}$ were based on personal observation of range sites and fell within the range of fetch lengths reported by de Soyza et al. (1997) and Whitford et al. (1999). In the second 


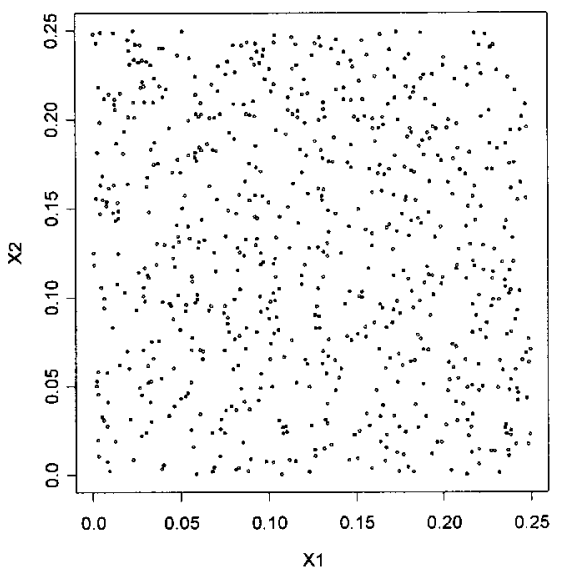

(a) random

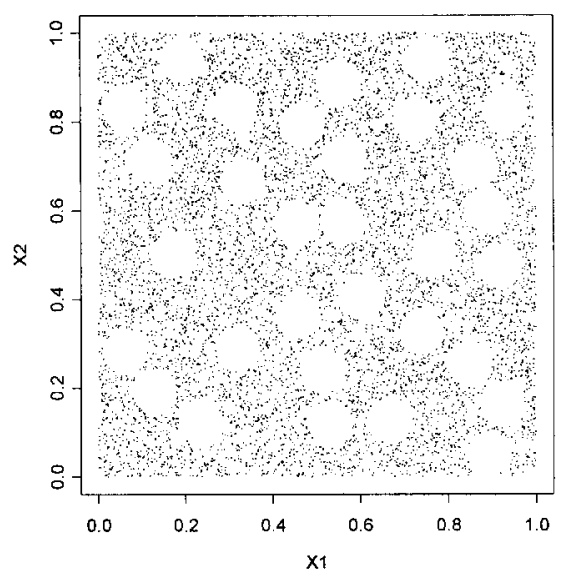

(b) fragmented
Fig. 1. Representative scenes at (a) a $10 \times 10 \mathrm{~m}$ scale to visualize the $5 \mathrm{~cm}$ discs simulating basal area in the random pattern and (b) at the $30 \times 30 \mathrm{~m}$ scale simulation to visualize the fragmented pattern.

stage, basal cover of $0.5 \%$, represented by the randomly distributed $5 \mathrm{~cm}$ discs, was generated within the bare patch areas because bare patches on range sites are typically not completely devoid of plant cover. In the third stage, the remaining $75 \%$ of the simulation surface outside the bare patches was populated with the $5 \mathrm{~cm}$ diameter discs in a random spatial distribution and were excluded from the simulated bare patches using the SSI algorithm. The coordinate points for the random distribution of $5 \mathrm{~cm}$ diameter discs and the $300 \mathrm{~cm}$ diameter bare patches were generated on a unit square with the X1 and X2 axes coordinates independently generated with a Uniform $(0,1)$ random number generator (ran2.c in Press et al. 1992).

\section{Line intercept samples}

Simulated line intercept transects were placed on these grassland simulations to generate the statistical distribution of distance between plants or fetch lengths. Two lines were generated to perform the line intercept measurements, each with a random starting point on the $\mathrm{X} 2$ axis of the unit square. The lines were scaled to a length of $30 \mathrm{~m}$ to span the simulated surface in the X1 axis direction. The measurement of intercept lengths on the lines were made using points at $1 \mathrm{~cm}$ intervals. The $1 \mathrm{~cm}$ distance was consistent with field methods that measure distances within $1 \mathrm{~cm}$. The measurement at each point was scored as a hit (1) on a $5 \mathrm{~cm}$ disc or miss (0). Thus, a series of successive $1 \mathrm{~s}$ or hits represented the length of intercept for plant basal cover and a series of successive 0 s or misses represented the length of distance between plants or fetch length.
The total number of hits (1s) were used to calculate the basal cover estimate, where there were 3,000 increments of $1 \mathrm{~cm}$ along each $30 \mathrm{~m}$ transect. The number of successive misses (0s) between any two hits (1s) on a line determined the magnitude of each fetch length.

\section{Point-to-nearest-event samples}

Random points were placed on these grassland simulations to generate the statistical distribution of distance from pointto-nearest-plant measurements. The number of random points necessary to adequately characterize the distribution of distances was equal to $\sqrt{\mathrm{N}}$, where $\mathrm{N}$ is the number of $5 \mathrm{~cm}$ discs generated for the simulated surface cover (Diggle 1983). The number of points generated per simulation scene to represent cover ranged from $\mathrm{N}=4,583$ for $1 \%$ cover to $\mathrm{N}=$ 68,754 for $15 \%$ cover.

\section{Descriptive statistics}

Descriptive statistics and their standard errors from 1,000 simulations were computed for a simple characterization of the sampling distributions for fetch lengths and random point-to-plant distances. The median was used to estimate the location of the distributions. The interquartile range between the $25^{\text {th }}$ and $75^{\text {th }}$ quartiles was used to estimate dispersion of the distributions. These parameters were used because they are resistant to the influence of outliers. A simple measure of sampling distribution asymmetry was constructed for these simulations so that it would be sensitive to outliers. This measure was called asymmetry and was computed as the ratio (maximum-median)/(median-minimum).
Thus, any asymmetry value greater than 1 would indicate a right skew distribution. We reasoned that this measure, especially for fetch length, would identify a condition with at least one very large open space or bare patch on a site. Furthermore, it was expected that the random point-to-plant distances and fetch lengths would produce right skewed asymmetric sampling distributions based on early trial simulations and field results given in deSoyza et al. (1997). In addition, the average basal cover with standard error estimate was computed for the simulations.

\section{Assessment of field measures}

Fetch length observations collected at 6 desert grassland sites on the Jornada Experimental Range in southern New Mexico were used to validate the characteristics of the fetch lengths from the simulations. Fetch lengths were measured on 15 different $10 \mathrm{~m}$ line intercept transects at 5 sites and on 14 transects at the 6th site (deSoyza et al. 1997). The 6 sites (EWC, ENC, MW1, WW3, MW3, and CW3) were selected from a larger group used by de Soyza et al. (1997) because all 15 transects on the selected sites had at least 1 fetch length measure. The absence of plants on at least 1 of the transects on each of the nonselected sites prohibited the measurement of fetch length which was necessary to calculate the descriptive statistics.

The median, IQR, and asymmetry statistics for the fetch lengths from these 6 sites were compared with the values from the simulations to assess the validity of the simulations and to assess the sensitivity of the statistics to differences in cover and non-random spatial distribution.

\section{Results}

\section{Line intercept measures}

The line intercept produced accurate measures of cover with the average of the 1,000 simulations nearly equal to the simulated cover (Table 1). The variability of the cover estimates for fragmented 5, 10 and $15 \%$ cover simulations was considerably higher than that for the random cover simulations. For example, the standard error was about $30 \%$ greater with fragmentation for the $5 \%$ cover simulations and about $60 \%$ greater for the $10 \%$ cover simulations (Table 1). The number of fetch lengths (on the 2 line intercepts combined) increased with cover and the numbers were virtually the same for random and fragmented distributions. 
Table 1. Means and standard errors (in parentheses) of fetch length statistics from 1,000 random and fragmented distributions as a function of simulated cover.

\begin{tabular}{|c|c|c|c|c|c|c|}
\hline \multirow{2}{*}{$\begin{array}{l}\text { Spatial } \\
\text { Distribution }\end{array}$} & \multirow{2}{*}{$\begin{array}{c}\text { Simulated } \\
\text { Cover }\end{array}$} & \multirow{2}{*}{$\begin{array}{c}\text { Estimated } \\
\text { Cover }\end{array}$} & \multirow{2}{*}{$\begin{array}{c}\text { Number of } \\
\text { Fetches }\end{array}$} & \multicolumn{3}{|c|}{ Fetch Length } \\
\hline & & & & Median & IQR & Asymmetry \\
\hline & $(\%)$ & $(\%)$ & - & \multicolumn{3}{|c|}{ 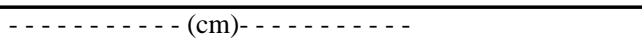 } \\
\hline Random & 1 & $100(.009)$ & $32(.25)$ & $266(3.2)$ & $426(5.5)$ & $4.5(.09)$ \\
\hline Fragmented & 1 & $100(.009)$ & $32(.25)$ & $272(3.2)$ & $428(5.6)$ & $4.4(.09)$ \\
\hline Random & 2.5 & $2.48(.013)$ & $77(.40)$ & $107(.80)$ & 169 (1.3) & $5.5(.08)$ \\
\hline Fragmented & 2.5 & $2.52(.015)$ & $78(.40)$ & $95(.81)$ & $174(1.6)$ & $7.1(.11)$ \\
\hline Random & 5 & $4.98(.018)$ & $153(.50)$ & $53(.27)$ & $82(.40)$ & $6.4(.07)$ \\
\hline Fragmented & 5 & $4.97(.023)$ & $152(.70)$ & $43(.25)$ & $76(.53)$ & $10.7(.12)$ \\
\hline Random & 10 & $9.98(.024)$ & $303(.70)$ & $25(.09)$ & $38(.15)$ & $7.2(.07)$ \\
\hline Fragmented & 10 & $9.97(.038)$ & $302(1.10)$ & $19(.07)$ & $31(.15)$ & $19.3(.15)$ \\
\hline Random & 15 & $15.00(.027)$ & $451(.80)$ & $16(.05)$ & $24(.07)$ & $7.7(.06)$ \\
\hline Fragmented & 15 & $14.95(0.57)$ & $449(.170)$ & $12(.04)$ & $18(.06)$ & $29.6(.21)$ \\
\hline
\end{tabular}

Regardless of the spatial distribution of the simulations, the median fetch length and the dispersion (IQR) of lengths decreased with increased cover while asymmetry increased with increased cover (Table 1, Fig. 2). The median fetch length for the fragmented distribution was less (between 4 and $12 \mathrm{~cm}$ ) than the random distribution when cover exceeded $1 \%$. The dispersion of fetch length for the fragmented distribution was less (about $6 \mathrm{~cm}$ ) than the random distribution when cover was at least $5 \%$.

The asymmetry measure was consistently greater than 1 regardless of amount of cover and spatial distribution, which indicates a highly right skewed sample distribution of fetch lengths (Table 1, Fig. 2). More importantly, asymmetry was the statistic that provided the most distinguishing contrasts between the random and fragmented distributions of cover. Asymmetry increased slightly with increased cover in the random distributions, from 4.5 at $1 \%$ cover to 7.7 at $15 \%$ cover. However, the asymmetry measure increased considerably with increased cover in the fragmented distribution, from 4.4 at $1 \%$ cover to 29.6 at $15 \%$ cover. Furthermore, at cover $\geq 5 \%$, asymmetry values did not exceed 8 for random distributions, but were $>10$ for the fragmented distributions.

median distances for the fragmented distribution were slightly larger than those from the random distributions. The dispersion

Table 2. Means and standard errors (in parentheses) for random point-to-plant distance statistics from 1,000 simulations of random and fragmented distributions as a function of simulated cover.

\begin{tabular}{lcccc}
\hline \hline $\begin{array}{l}\text { Spatial } \\
\text { Distribution }\end{array}$ & $\begin{array}{c}\text { Simulated } \\
\text { Cover }\end{array}$ & Median & IQR & Asymmetry \\
\hline Random & $(\%)$ & $-------(\mathrm{cm})-----\cdots$ & $1.9(.02)$ \\
Fragmented & 1 & $20.8(.06)$ & $16.2(.08)$ & $2.1(.02)$ \\
Random & 1 & $20.9(.06)$ & $16.7(.08)$ & $2.0(.02)$ \\
Fragmented & 2.5 & $13.0(.03)$ & $10.0(.04)$ & $3.6(.03)$ \\
Random & 2.5 & $13.4(.03)$ & $11.6(.05)$ & $2.0(.01)$ \\
Fragmented & 5 & $8.9(.02)$ & $6.9(.02)$ & $5.6(.03)$ \\
Random & 5 & $9.4(.02)$ & $9.0(.04)$ & $2.0(.01)$ \\
Fragmented & 10 & $6.1(.01)$ & $4.5(.01)$ & $9.0(.05)$ \\
Random & 10 & $6.4(.01)$ & $6.8(.03)$ & $2.0(.01)$ \\
Fragmented & 15 & $4.9(.01)$ & $3.5(.01)$ & $11.8(.06)$ \\
\hline
\end{tabular}

\section{Point-to-nearest-event distances}

Regardless of simulation type, the median point-to-nearest-plant and the dispersion (IQR) of distances decreased with increased cover (Table 2, Fig. 3). The

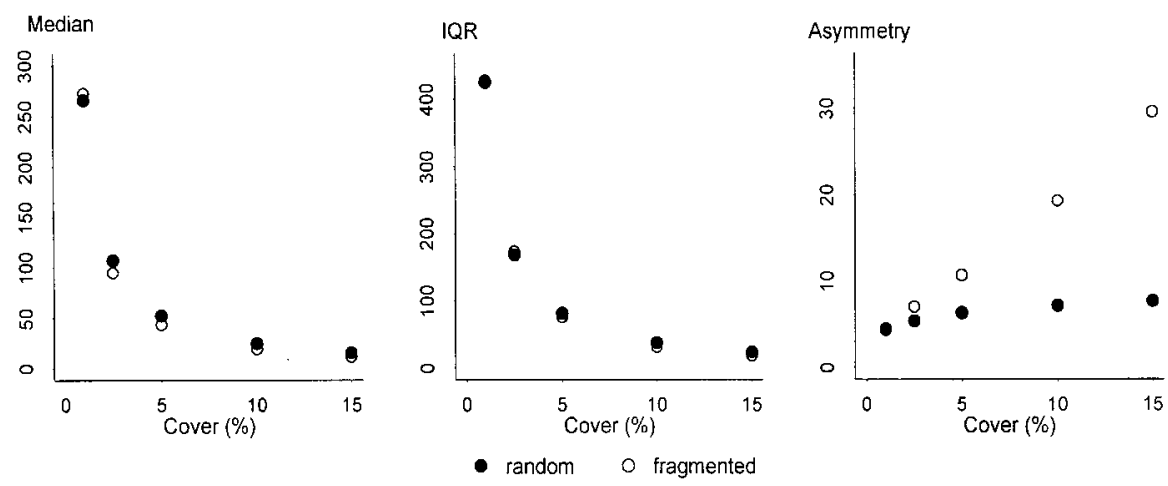

Fig. 2. Relationships between percent cover and descriptive statistics of median, interquartile range (IQR), and asymmetry for fetch lengths measured from random and fragmented spatial cover simulations. of the point-to-nearest-event distances were slightly greater (from 0.5 to $2.3 \mathrm{~cm}$ ) for the fragmented than the random distributions. Asymmetry for random distributions had a value of 2 for all of the simulations except for the $1 \%$ cover with an asymmetry value of 1.9 . In contrast, asymmetry with fragmented simulations increased sharply with cover from 2.1 for $1 \%$ cover to 11.8 for $15 \%$ cover.

\section{Field Data}

The cover estimates for total vegetation measured from the line intercepts at the 6 field sites ranged from 3.4 to $8.6 \%$ with values of median, IQR, and asymmetry (Table 3 ) within the range of values observed for the random and fragmented spatial distribution simulations (Tables 1, 2). The median fetch length and IQR decreased with increased cover (Table 3, Fig. 4). The relationship between cover and the median for the field sites was sim- 

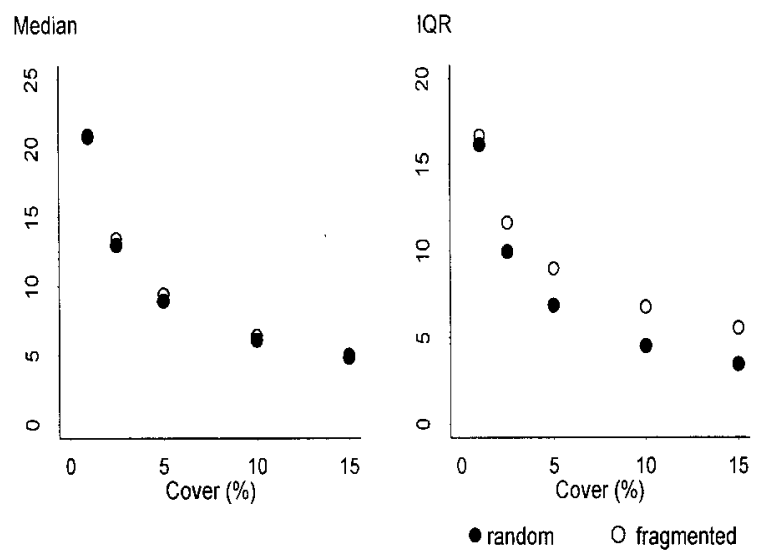

Fig. 3. Relationships between percent cover and descriptive statistics of median, interquartile range (IQR), and asymmetry for random points-to-nearest-plant distances measured from random and fragmented spatial cover simulations.
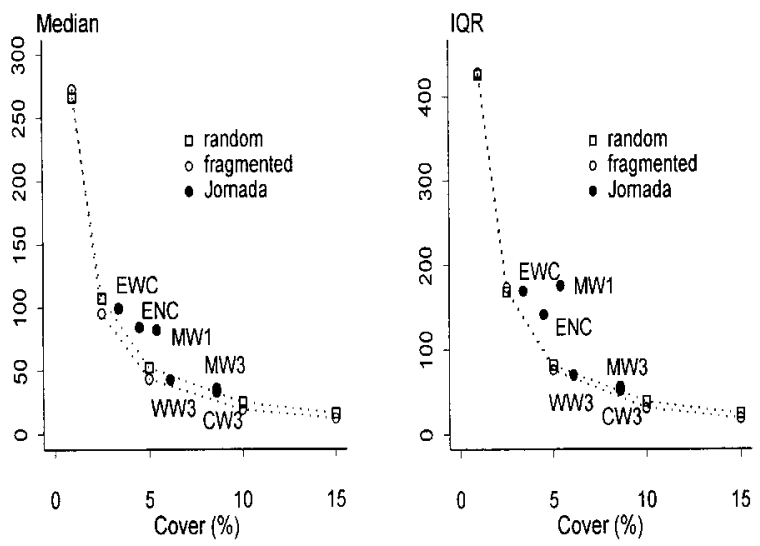

Fig. 4. Relationships between estimated cover and median, interquartile range (IQR), and asymmetry from field measured fetch lengths (Jornada) and from random and fragmented spatial cover simulations.

ilar to values from the simulations, except the MW1 site had greater median and IQR values than expected (Fig. 4).

The values for asymmetry from the field sites were within the range of values from the random and fragmented distribution simulations measured with fetch lengths on the line intercept transect (Fig. 3). A close examination of the asymmetry values from sites MW3 and CW3 illustrates how the asymmetry statistic can be used to differentiate sites with different levels of fragmentation even though the sites have equivalent cover $(8.6 \%)$, median fetch length $(36$ and $33 \mathrm{~cm})$, and IQR (56 and 52) values.

\section{Discussion}

Fetch lengths appear to provide a credible surrogate for assessing the behavior of point-to-nearest-plant distances on monitoring sites, because the behavior of fetch length statistics from the line intercept
Asymmetry
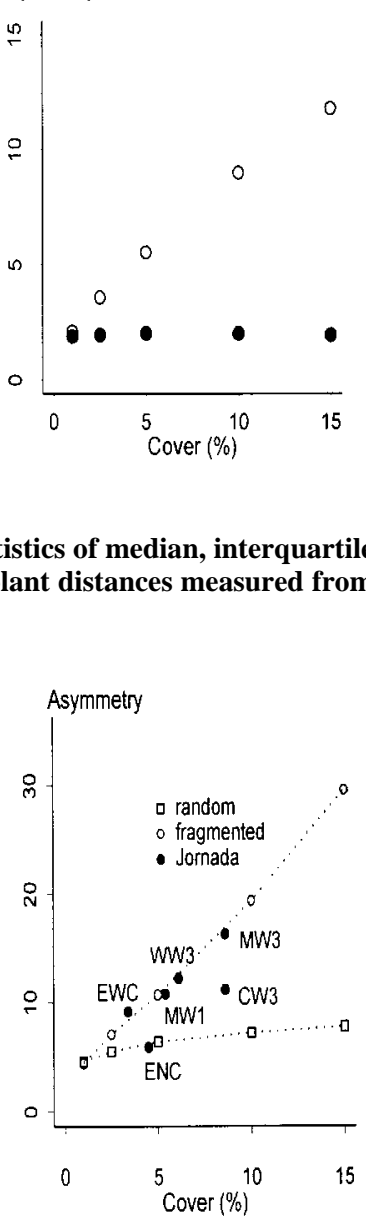

only slightly with increasing cover. Conversely, for the fragmented spatial distributions, the asymmetry values increased markedly with increasing cover for both methods.

Asymmetry was the only statistic of the 3 evaluated that could be used to distinguish random from fragmented spatial distributions, and this was obvious when using either the fetch length or point-toplant methods. The critical asymmetry value to distinguish fragmented distributions using the fetch length method was 8 for these simulations because it was never attained in the samples from the random distributions, but was exceeded in all fragmented distributions with $\geq 5 \%$ cover.

The analysis of fetch lengths from line intercepts taken at 6 desert grassland locations support the validity of the simulations for plant cover and the sample distributions for fetch lengths. Furthermore, the field results support the use of the asymmetry statistic to detect deviations from random spatial distributions of plant cover.

The positive relationship between asymmetry and patchiness of plant distribution suggests that fetch lengths measured on line intercept transects can distinguish between changes in absolute cover and changes in the spatial arrangement of cover. Increased fetch distances between plants indicate a decline in absolute cover. Independent of these changes in absolute cover, a change in the asymmetry statistic indicates a change in the spatial distribution of the cover.

These simulation and field validation results support the use of fetch length measure taken along a line intercept transect as a means of estimating both absolute cover and the spatial arrangement of that cover. Therefore, we support continued research and development to incorporate fetch length measures into existing line intercept transect protocols for monitoring rangeland vegetation.

Table 3. Descriptive statistics for fetch lengths measured from six sites on the Jornada Experimental Range, New Mexico.

\begin{tabular}{|c|c|c|c|c|c|c|c|}
\hline \multirow[b]{2}{*}{ Site } & \multirow{2}{*}{$\begin{array}{c}\text { Total Plant } \\
\text { Cover } \\
\text { Estimate }\end{array}$} & \multirow{2}{*}{$\begin{array}{c}\text { Grass/Forb } \\
\text { Cover } \\
\text { Estimate }\end{array}$} & \multicolumn{5}{|c|}{ Fetch Length } \\
\hline & & & Minimum & Maximum & Median & IQR & Asymmetry \\
\hline & $(\%)$ & $(\%)-$ & $-\cdots-\cdots$ & $\cdots-\cdots$ & 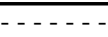 & $-\ldots$ & \\
\hline EWC & 3.4 & 2.5 & 2 & 985 & 99 & 170 & 9.1 \\
\hline ENC & 4.5 & 4.2 & 3 & 560 & 84 & 142 & 5.9 \\
\hline MW1 & 5.4 & 1.9 & 2 & 946 & 82 & 176 & 10.8 \\
\hline WW3 & 6.1 & 5.8 & 3 & 531 & 43 & 70 & 12.2 \\
\hline MW3 & 8.6 & 8.2 & 1 & 606 & 36 & 56 & 16.3 \\
\hline CW3 & 8.6 & 8.3 & 2 & 379 & 33 & 52 & 11.2 \\
\hline
\end{tabular}




\section{Literature Cited}

Canfield, R.H. 1941. Application of the line intercept method in sampling range vegetation. J. For. 39:388-394.

de Soyza, A.G., W.G. Whitford, and J.E. Herrick. 1997. Sensitivity testing of indicators of ecosystem health. Ecosystem Health 3:44-53.

Diggle, P.J. 1983. Statistical Analysis of Spatial Point Patterns. Academic Press, London.

Kaiser, L. 1983. Unbiased estimation in lineintercept sampling. Biometrics 39:965-976.

Matérn, B. 1960. Spatial Variation. Meddelanden från Statens Skogsforskningsinstitut 49,5 1-114.
National Research Council. 1994. Rangeland health: new methods to classify, inventory, and monitor rangelands. National Academy Press, Washington, D.C.

Press, W.H., S.A. Teukolsky, W.T. Vetterling, and B.P. Flannery. 1992. Numerical Recipes in C. The Art of Scientific Computing, $2^{\text {nd }}$ ed., Cambridge University Press, New York, N.Y.

Schlesinger, W.H., J.F. Reynolds, G.L. Cunningham, L.F. Huenneke, W.M. Jarrell, R.A. Virginia, and W.G. Whitford. 1990. Biological feedbacks in global desertification. Sci. 247:1043-1048.

Tongway, D. and N. Hindley. 1995. Manual for Soil Condition Assessment of Tropical Grasslands. Division of Wildlife and Ecology, CSIRO, Canberra, Australia.
Weltz, M.A., M. Kidwell, and H.D. Fox. 1998. Influence of abiotic and biotic factors in measuring and modeling soil erosion on rangelands: state of knowledge. J. Range Manage. 51:482-495.

Whitford, W.G., A.G. deSoyza, J.W. Van Zee, J.E. Herrick, and K.M. Havstad. 1998. Vegetation, soil and animal indicators of rangeland health. Environ. Monitor. and Assess. 51:179-200.

Whitford, W.G., J. Van Zee, M.S. Nash, W.E. Smith, and J.E. Herrick. 1999. Ants as indicators of exposure to environmental stressors in North American desert grasslands. Environ. Monitor. and Assess. $54: 143-171$.

Statement of Ownership, Management, and Circulation

(Act. of August 12, 1970, Sec. 3685, Title 39, United States Code)

1. Title of Publication: Journal of Range Management

2. Date of Filing: September 22, 2000

4. Location of Office of Publication: 445 Union Blvd., Suite 230, Lakewood, Colorado 80228

5. Location of General Business Office: Same

6. Name and Address of:

Publisher: Society for Range Management, 445 Union Blvd., Suite 230, Lakewood, Colorado 80228

Editor: Gary Frasier, 7820 Stag Hollow Road, Loveland, Colo. 80538

Managing Editor: J. Craig Whitekiend, 445 Union Blvd., Suite 230, Lakewood, Colorado 80228

7. Owner: Society for Range Management, 445 Union Blvd., Suite 230, Lakewood, Colorado 80228

8. Known Bondholders, Mortgages, etc.: Membership

9. For Completion by Nonprofit Organizations Authorized to Mail at Special Rates: The purpose, function, and nonprofit status of this organization and the exempt status for Federal income tax purposes have not changed during preceding 12 months.

10. Extent and Nature of Circulation

A. Total copies printed

$\begin{array}{cc}\text { Avg. for } & \begin{array}{c}\text { Actual for } \\ \text { issue neares } \\ \text { filing date } \\ 2,706\end{array} \\ 2,769 \\ 0 & 0 \\ 2,434 & 2,528 \\ 2,434 & 2,528 \\ 22 & 22 \\ 2,456 & 2,550 \\ 250 & 219 \\ 2,706 & 2,769\end{array}$

1. Dealers, counter sales

2. Mail subscriptions

C. Total paid circulation

D. Free distribution

E. Total distribution

F. Copies not distributed

2,706

219
2,769

I certify that the statements made by me above are correct and complete -J. Craig Whittekiend, Managing Editor. 